\title{
PLANOS DE GOVERNO SÃO \\ ESSENCIAIS PARA A ESCOLHA \\ DO PRÓXIMO PRESIDENTE
}

Coluna publicada em 21.10.2014: $<$ http://www.conjur.com.br/2014-out-21/ contas-vista-planos-governo-sao-essenciais-escolher-proximo-presidente>

Neste domingo, decidiremos quem será o novo Presidente da República e, em muitos Estados da Federação, serão definidos os Governadores.

A escolha de um candidato a Presidente ou Governador, desnecessário falar, é decisão extremamente importantes e deve ser muito bem refletida.

Para isso, o mínimo que cada eleitor deve fazer é analisar bem os candidatos e, principalmente, seus planos de governo, em que devem estar expressas as posições que pretendem adotar naquela que é seguramente sua principal função: a condução da administração pública pelo período do mandato.

Chamou a atenção nessas eleições o aparente desprezo que a maior parte dos candidatos demonstrou pela apresentação do plano de governo, muitos deixando para fazê-lo já no meio da campanha, alguns divulgando documentos genéricos e simplificados, outros sequer o apresentando, outros ainda sendo acusados de ter um programa "escrito a lápis" e tantas outras manifestaçôes de desapreço por aquele que deveria ser o principal documento no qual o eleitor deve se basear para escolher seu candidato. ${ }^{1}$ Ajustes nesses "planos de governo" ao longo da campanha, ao sabor da repercussão que observam na mídia para diversas questões, evidenciam uma inequívoca improvisação de um governo que terá de começar a trabalhar poucos meses após as eleições.

1 Aécio diz que seu programa de governo “virá a caneta, não a lápis”. Valor Econômico, 23 de setembro de 2014, entre outras notícias sobre o assunto. 
A obrigação imposta pela legislação eleitoral, de exigir as propostas defendidas pelo candidato por ocasião do registro da candidatura, ${ }^{2}$ é cumprida, muitas vezes, com desdém, como se fosse uma formalidade equivalente a juntar fotografia e certidôes criminais. Para os eleitores que quiserem consultar, as propostas registradas por todos os candidatos junto ao Tribunal Superior Eleitoral estão disponíveis no endereço eletrônico ${ }^{3}$ onde podem ser encontradas as propostas dos atuais postulantes à Presidência, candidatos Dilma Rousseff (Mais mudanças, mais futuro, 25 páginas) e Aécio Neves (Diretrizes gerais - plano de governo - Aécio Neves - PSDB 2014, 76 páginas).

O mínimo que se espera de um postulante à Presidência da República é que ele saiba o que pretende fazer ao assumir o cargo e deixar isso claro a seus eleitores, permitindo que estes possam escolher estadistas, e não personalidades; que possam eleger com base em programas, e não em pessoas.

Como já defendi anteriormente, ${ }^{4}$ deveria a legislação exigir que os candidatos apresentassem um plano de governo detalhado, verdadeira antecipação do plano plurianual (PPA), por ocasião do registro da candidatura, de modo a obrigá-los não somente a pensarem, refletirem e construírem uma linha de conduta para seu período de governo, como também criar um documento que permita ao eleitor cobrar o candidato eleito após assumir o cargo, exigindo o cumprimento dos compromissos assumidos.

Nesse sentido está a previsão do artigo $6^{\circ}, \$ 2^{\circ}$, do projeto de Lei de Qualidade Fiscal, em tramitação no Congresso Nacional com vistas a substituir a Lei 4.320, de 1964, que regula os orçamentos públicos. ${ }^{5}$ Prevê a redação que "o $\mathrm{PPA}^{6}$ considerará o plano de governo do candidato eleito Chefe do Poder executivo, devendo todos os candidatos registrar o respectivo plano de governo na Justiça Eleitoral em até dois meses antes da data do pleito eleitoral, em primeiro e único turno".

Evidentemente, não há como exigir nesse documento o mesmo detalhamento do PPA, até porque o candidato só terá pleno conhecimento da administração

2 Lei 9.504 de 30 de setembro de 1997, art. 11, $\$ 1^{\circ}$ : "O pedido de registro deve ser instruído com os seguintes documentos: IX - propostas defendidas pelo candidato a Prefeito, Governador de Estado e a Presidente da República” (redação dada pela Lei 12.034, de 2009).

3 <divulgacand2014.tse.jus.br/divulga-cand-2014/menu/2014>.

4 Coluna No primeiro ano de mandato, não se cumprem promessas, publicada em 20 de novembro de 2012.

5 BRASIL, Senado Federal, Comissão de Constituição, Justiça e Cidadania. Parecer do relator, Senador Arthur Virgílio, sobre os Projetos de Lei do Senado 229 e 248, de 2009.

6 Plano Plurianual, previsto no art. 165, I da Constituição. 
pública e poderá dispor das informações necessárias após assumir o cargo. Exceção feita aos que se candidatam à reeleição, que têm a obrigação, ainda que não legal, de apresentar um plano minucioso e detalhado dado o privilégio de estar conduzindo a administração há mais de três anos, com todas as informações à sua disposição, além da experiência adquirida. Mesmo assim, vê-se que muitos não o fazem.

A função precípua do Presidente da República é conduzir a gigantesca máquina da administração pública federal, cujo orçamento para este ano de 2014 está na ordem de R \$ 2,5 trilhões, ${ }^{7}$ e não se pode fazê-lo sem um planejamento sério, confiável, detalhado e bem elaborado. A Constituição atribui ao Presidente da República remeter ao Congresso Nacional o plano de governo no início de cada sessão legislativa (art. 84, XI), enviar ao Congresso Nacional os projetos de PPA (Plano Plurianual), da lei de diretrizes orçamentárias (LDO) e da lei orçamentária anual (art. 84, XXIII) e, findo o exercício financeiro, prestar contas das atividades financeiras realizadas (art. 84, XXIV).

Atualmente, o principal instrumento de planejamento governamental é o plano plurianual, que, embora tenha um viés orçamentário, é o que está sendo utilizado para materializar juridicamente o plano de governo dos entes da federação. $\mathrm{O}$ projeto de PPA federal deve ser elaborado e encaminhado ao Congresso Nacional em até oito meses após a posse, ${ }^{8}$ o que só pode ser feito se o candidato já tem estabelecidas suas prioridades e, respeitando aqueles que o elegeram, deve elaborá-lo de acordo com os compromissos que assumiu em sua campanha e o levaram à vitória nas eleições. Em alguns entes da Federação, o prazo é ainda mais curto, como é o caso do Município de São Paulo, que, sem prejuízo do plano plurianual, adota o Programa de Metas, que prevê a apresentação de um detalhado planejamento até 90 dias após a posse.?

Releva notar, na linha do que se observa, um forte desprezo pelo planejamento governamental, que, em muitos casos, cabe ao governante apenas priorizar ações já previstas e em andamento, uma vez que o planejamento já existe, cabendo-lhe apenas cumprir a parte que lhe cabe no período do mandato. $\mathrm{O}$ melhor exemplo está na educação, em que, após longos e intensos debates, foi recentemente aprovado (com atraso de quatro anos) o Plano Nacional de Educação (PNE) $;^{10}$ setor em

\footnotetext{
7 Orçamento da União para 2014 - Lei 12.952, de 20 de janeiro de 2014.

8 Constituição Federal, ADCT, artigo $35, \$ 2^{\circ}$, I: “o projeto do plano plurianual, para vigência até o final do primeiro exercício financeiro do mandato presidencial subsequente, será encaminhado até quatro meses antes do encerramento do primeiro exercício financeiro".

9 Lei Orgânica do Município de São Paulo, artigo 69-A.

10 Lei 13.005, de 25 de junho de 2014.
} 
que já estão estabelecidas, em detalhes, as prioridades e metas da administração pública para os próximos dez anos, de modo que caberá aos eleitos apenas e tão somente definir, do que já está previsto, o que será feito no período de seu mandato. E mesmo assim, isso não é feito, ou sequer levam o PNE em consideração.

É interessante observar também, ao acompanhar as campanhas eleitorais, um desconhecimento sobre as competências do Presidente da República. Da mesma forma que muitos candidatos ao Poder Legislativo levantam bandeiras de temas diretamente relacionados às funçôes do Poder Executivo, fazendo promessas que não estão em sua alçada de atribuições, como realização de obras públicas, execução de tarefas e implementação de políticas públicas, por vezes até da responsabilidade de outro ente da federação, o inverso também se constata.

O candidato a Presidente da República, a quem cabe exercer o comando do Poder Executivo Federal, é chamado a opinar sobre temas como redução da maioridade penal, aborto, legalização de drogas, orientação sexual e outros que, não obstante importantes, devem ser objeto de debate e deliberação no âmbito do Poder Legislativo.

Já questôes que estão entre suas atribuições são pouco mencionadas, como a política externa, uma vez ser de competência privativa do Presidente da República manter relações com estados estrangeiros e celebrar tratados, convenções e atos internacionais (CF, art. 84, VII e VIII), bem como exercer o comando supremo das Forças Armadas (art. 84, XIII) e declarar guerra (art. 84, XIX).

Outros temas da maior relevância, embora sejam da alçada do Poder Legislativo, dependem fortemente da participação do Poder Executivo, que deve construir um bom projeto para levar ao debate. É o caso, citando um exemplo no âmbito do Direito Financeiro, da sempre presente "reforma tributária" - que, na verdade, é financeira, uma vez que as principais questôes referem-se às atribuições de competências tributárias e partilhas de receitas, exigindo uma reconstrução do federalismo fiscal, com forte impacto nas relações entre os entes federados, muito mais difíceis de ajustar que as relações tributárias entre fisco e contribuintes. O receio de desagradar uns e outros e a vontade de tentar agradar a todos levam à opção pelo silêncio sobre o tema ou a referência a propostas vagas, impedindo que o eleitor saiba o que o candidato pretende fazer nesta e em outras questóes, como se pode constatar ao consultar as propostas de governo de praticamente todos os candidatos.

A verdade é que, como já tive oportunidade de mencionar anteriormente, ${ }^{11} \mathrm{o}$ planejamento claro e transparente, fundamental para uma gestão pública eficiente,

11 Planejamento municipal precisa ser levado a sério, publicada em 24 de setembro de 2013. 
importa em escolher prioridades. E, por consequência, indicar o que e quem não será contemplado pelo novo governo - e isso nenhum candidato quer fazer. ${ }^{12}$

Os planos de governo apresentados pelos candidatos estão aí (Aécio Neves Brasil: o novo jeito de governar - Plano de governo de Aécio Neves e Aloysio Nunes 2015-2018, 273 páginas; e Dilma Rousseff - Mais mudanças, mais futuro - Programa de Governo Dilma Rousseff-2014, 42 páginas) ${ }^{14}$ e, embora pouco conhecidos e divulgados, devem ser a ferramenta para a escolha do próximo domingo. Ainda é tempo de analisá-los e votar naquele que melhor represente você, leitor e eleitor e mostre ser capaz de conduzir a administração pública em direção aos objetivos fundamentais consagrados pela Constituição.

12 Coluna Planejamento municipal precisa ser levado a sério, publicada em 24 de setembro de 2013.

13 <www.aecioneves.com.br>.

$14<$ www.dilma.com.br>. 
